\title{
THE FIRST OUTCOME RESULTS OF THE MID-POINT CURRICULUM ASSESSMENTS FOR COMPUTER PROGRAMMING AND INFORMATION TECHNOLOGY STUDENTS
}

\author{
John J. Scarpino, Pittsburgh Technical College, scarpino.john@ptcollege.edu \\ Wilfred Mutale, Pittsburgh Technical College, mutale.wilfred@ptcollege.edu \\ Charles Eltringham, Pittsburgh Technical College,eltringham.charles@ptcollege.edu \\ Philip Grabowski, Pittsburgh Technical College, grabowski.philip@ptcollege.edu \\ Mel Tomeo, Pittsburgh Technical College, tomeo.mel@ptcollege.edu \\ Theophilus D.Owusu, Keiser University, towusu@keiseruniversity.edu
}

\begin{abstract}
Courses in Computer Programming and Information Technology are in high demand, as industry embraces the needs and requirements to embed technology in every business need. The authors of the paper are from a Technical College located in Pittsburgh, PA who have implemented and developed their departments' first mid-point student assessment towards their curriculum. This paper will focus on the data finding results and action plans from the student assessment for Computer Programming and Information Technology Associate degree programs and academic curriculum outcome results from the students' mid-point test assessments. This research hopes to add assistance to other Computer Programming / Information Systems and Information Technology / Data Communications curriculums.
\end{abstract}

Keywords: Academic Assessments, Curriculum, Computer Programming, Information Technology, Information Systems, Data Communications, Higher Education, College, University, Courses, Classes, Student Assessments.

\section{INTRODUCTION}

Courses in Computer Programming and Information Technology are growing in demand as we see other disciplines shrink. In the Journal of Information Technology Education, Zhang and Aasheim indicated "according to the U. S. Department of Labor the demand for employment in IT-related professions will grow much faster than the average for all occupations through to the year 2018. The Bureau of Labor statistics projects a 53\% increase between 2008 and $2018 \ldots$ jobs within these fields also require at least a Bachelor's degree" (2011).

Pittsburgh Technical College (PTC) implemented in the spring of 2016 its first formal student mid-point assessment to ensure its two programs: Computer Programming and Information Technology. Students who were in these programs started in October 2015. PTC is a nationally-ranked top 50 Technical College by Community College Weekly within the two categories of Top 50 Associate Degrees: Engineering Technologies and Engineering-Related Fields and Top 50 Associate Degrees: Computer and Information Sciences \& Support Services ("Top 50 Charts," 2016), located in Oakdale, Pa., a suburb of Pittsburgh.

When we deal with program curriculum... it is very important to assess students' abilities, as Valenti stated: "Assessment plays a central role in the educational process. In the last few years, the scientific community has seen development of new assessment methodologies and novel tools applying Information Technology to the assessment process of student learning" (2003).

At Pittsburgh Technical College, all of the classes build upon each other and the students learn both philosophically and with applied approaches. PTC created many industry partnerships, driving the current innovations within industry to the classroom, while at the same time giving the students the traditional theoretic of the subject matter. Valenti states it clearly when he said: 
Active learning and cooperative learning are two alternatives to the traditional lecture/lab approach to teaching software development [and furthermore IT]. Evidence supporting use of these learning strategies in Computer Information Systems began to emerge in the mid-1990s as faculty sought ways to improve student understanding of programming concepts [and further more IT], reduce the level of frustration, and better prepare students for jobs based on teamwork (2003).

When Computer Programming and Information Technology are discussed, it is very important to distinguish the differences between the two. Reichgelt, Lunt, Ashford, Phelps, Slazinski and Willis defines Information Systems [Computer Programming] as:

A field of academic study encompasses the concepts, principles and processes for two broad area of activity within organizations: (1) acquisition, deployment, and management of information technology resources and services (the information systems function) and (2) development, operation, and evaluation of infrastructure and systems for use in organizations process (system development, system operation, and system maintenance. While Information Technology is defined as an academic discipline that focuses on meeting the needs of users in an organizational and societal context through the selection, creation, application, integration and administration of computing technologies.

It is important to denote that IT specialists are people with generally "deep technical skills and narrow scope, giving them expertise that is recognized by peers, but it is seldom known outside of their immediate areas" (Koohang, Riley, Smith, Floyd, 2010).

When a student selects a course they "are in an unenviable position as a stakeholder in IS curriculum design. They have the least power to influence the curriculum, yet stand to lose the most if it is poorly designed. The only control that they have is in selecting a college to attend and choosing electives. With this narrow scope, students tend to pursue a very conservative "path of least resistance" strategy of graduation" (Lightfoot, 1999).

This study focuses on the data findings of the mid-point student assessment results for Computer Programming and Information Technology programs, and discusses the outcome and results of the School of Technology's first assessment within its curriculum. This research aims to assist other Computer Programming and Information Technology administrators, faculty and curriculums.

\section{LIMITATIONS OF STUDY}

Participants in the mid-assessment were Associate of Science (A.S.) students who started in two separate programs in October 2015: Computer Programming (CP) and Information Technology (IT). The tests for these assessments were given in the Spring of 2016. The total number of Computer Programming students who took the assessment test was 41; the total number Information Technology students who took the assessment was 35.

\section{RESEARCH METHODOLOGY}

This study was given to both Computer Programming and Information Technology classes separately during their mid-point term of Spring 2016. The test consisted of 10 multiple choice items, four short question responses, and a programming lab for Computer Programming. The test consisted of 100 multiple-choice questions for Information Technology. The students were given two hours to complete the assessment and finish the tests. Each of the test questions and labs were given a Program Outcome.

The total number Computer Programming students who took the assessment test was 41, and the total number of Information Technology students who took the assessment was 35. The questions for each of the tests for Computer Programming and Information Technology were derived from the required Program Outcomes, as designated below: 
Computer Programming:

Program Outcome 1 - Create desktop, web based and mobile device applications using standard programming languages.

Program Outcome 2 - Develop and enhance problem solving skills as applied to software development.

Program Outcome 3 - Develop software using the Object Oriented Programing principles; inheritance, polymorphism and encapsulation.

Program Outcome 4 - Exhibit professional growth and meet the industry expectations of Computer Programming students.

Information Technology:

Program Outcome 1 - Configure, troubleshoot, and administer client or network operating systems.

Program Outcome 2 - Plan, design, and develop a functional and secure network infrastructure.

Program Outcome 3 - Implement support models based on best practices.

Program Outcome 4 - Exhibit professional growth and meet the industry expectations of Information Technology Network Administration students.

\section{RESULTS}

Below are the results and action plans of the two mid-point assessments for Computer Programming and Information Technology.

\section{Computer Programming:}

Program Outcome 1 - Create desktop, web based and mobile device applications using standard programming languages.

Results: Computer Programming students essentially understood the standard desktop programming concepts. The above satisfactory comprehension exists due the repetitious coding, documenting, and debugging programs in the languages of Java and C++ in all three of their first quarters. An area for improvement was the students' inability to handle exceptions, and a mechanism to handle the logical errors so that normal flow of a Java application can be maintained. Students are not exposed to Web-based and Mobile programming procedures until the fourth, fifth, and sixth quarter. Once students have completed assigned programming labs, they do not research other possibilities in solving the indicated program.

Computer Programming students comprehend basic programming structures in the Java and $\mathrm{C}++$ languages. They can code, document, and debug programs. This occurs due to the repetition of the completion of lab programs. Students resist reading the material thoroughly. They skim the material and read similar code that pertains to their programs.

Action Plan: More Quantitative (questions) with Qualitative (Programs) should be included when assessing knowledge of programming language concepts in the SSD 152 Introduction to Information Systems and SSD 301 Object Oriented Programming. Students should be provided with more preparation in analyzing and debugging existing programs. Also, students should have lab programs that are partially completed and they must computer program the remaining code to fulfill the lab exercise criteria. Computer programming students will develop more familiar with programming structures, effective debugging, and to code/test/adjust to examine their own intellectual weaknesses and strengths so that they can better prepared to be current with basic programming languages.

Program Outcome 2 - Develop and enhance problem solving skills as applied to software development.

Results: Computer Programming students established the ability to track and implement program language instructions. The above satisfactory understanding exists due the constant exposure to coding, documenting, and debugging programs in the languages of Java and $\mathrm{C}++$. An area for improvement was the inability to apply detailed formatting for data output. Students demonstrated a fault in coding or modifying code to enhance the appearance of data in output streams, which implement either character stream classes. Computer Programming students established 
the ability to comprehend and follow coding instructions well. They can utilize the Java API website to research procedures and error statements in debugging their program code. They were not able to enhance data to output streams due to the insufficient practice formatting of output data.

Action Plan: Computer Programming students need to read materials carefully, more classroom discussion/labs need to be utilized to reinforce concepts, and possible study/lab groups to solve advanced computer programming issues. Include more Quantitative (questions) with Qualitative (Programs) when assessing knowledge of programming and troubleshooting skills. Students should have more lab exercises in analyzing and debugging existing programs in the SSD 152 Introduction to Information Systems and SSD 301 Object Oriented Programming classes.

Program Outcome 3 - Develop software using the Object Oriented Programing principles; inheritance, polymorphism and encapsulation.

Results: Computer Programming students developed a basic knowledge of Object-oriented programming concepts. Students established above average understanding of Inheritance (concept in which a class of objects is defined, any subclass that is defined can inherit the definitions of one or more general classes) and Polymorphism (allowing an entity such as a variable, a function, or an object to have more than one form) the basic programming concepts. The above satisfactory comprehension exists due to the repetitious coding, documenting, and debugging programs in the languages of Java and $\mathrm{C}++$ in all three of their first quarters.

An area of apprehension is the ability to apply encapsulation (inclusion of all methods and variables needed for a Java object to function, contained within the object itself) concepts. Computer Programming students are introduced to the concept of encapsulation but were not tested via the existing computer programming midpoint. Students show knowledge of basic Object-oriented programming concepts (creation of classes). Students were able to utilize Inheritance and Polymorphism concepts in their development of programming code in Java and $\mathrm{C}++$ languages.

Action Plan: Computer Programming students established the ability to utilize basic Object-oriented programming concepts in many Java and C++ programming lab practices and valuations in the SSD 152 Introduction to Information Systems, SSD 301 Object Oriented Programming, and ITP211 Programming Mobile Applications. The program wishes to incorporate more Quantitative (questions) with Qualitative (Programs) when assessing comprehension of programming and troubleshooting skills. The program also plans to provide students more preparation in analyzing and debugging existing Java and $\mathrm{C}++$ programs.

Program Outcome 4 - Exhibit professional growth and meet the industry expectations of Computer Programming students.

Results: Several Computer Programming students displayed above-average levels of professional growth and meeting the industry expectations of Information Technology / Computer Programming professionals. There were a few students that performed at an extraordinary level. Computer Programming students displayed the ability to apply prior knowledge and previous learned practices to similar situations/problems. They can plan, code, test/debug, and document basic Object-oriented programs ( $\mathrm{C}++$ and Java). They rely on the API Website for reinforcement of coding and programming concepts.

Action Plan: Computer Programming students need to read materials carefully, more discussion and programming labs need to be utilized to strengthen coding procedures, flowcharting, and documentation of programs that were introduced in the first three quarters (Introduction to Information Systems, SSD 301 Object Oriented Programming, ITP202 Project Management and ITP211 Programming Mobile Applications). Also, encourage students to discover other best practices besides the one in the text books. 
Table 1. Computer Programming Average Score Breakdown

\begin{tabular}{|l|c|}
\hline \multicolumn{1}{|c|}{ Program Outcome for Computer Programming } & Average Score \\
\hline $\begin{array}{l}\text { P1 - Create desktop, web based, and mobile device applications using } \\
\text { test driven design principles and incorporating standard programming } \\
\text { languages. }\end{array}$ & $90 \%$ \\
\hline $\begin{array}{l}\text { P2 - Develop and enhance problem solving skills as applied to software } \\
\text { development. }\end{array}$ & $90 \%$ \\
\hline $\begin{array}{l}\text { P3 - Develop software using the Object Oriented Programing principles: } \\
\text { inheritance, polymorphism, and encapsulation. }\end{array}$ & $90 \%$ \\
\hline $\begin{array}{l}\text { P4 - Exhibit professional growth and meet the industry expectations of } \\
\text { Computer Programming students. }\end{array}$ & $90 \%$ \\
\hline
\end{tabular}

\section{Information Technology:}

Program Outcome 1 - Configure, troubleshoot, and administer client or network operating systems. Results: Information Technology students fundamentally grasp the basic network concepts. The above satisfactory comprehension exists due the repetitious presentation, installation, and practice of network and networking concepts in all three of their first quarters.

An area of apprehension is the ability to plan troubleshooting processes. Students demonstrate a weakness in identifying the processes needed to troubleshoot an existing problem they are un-familiar with, test the results from the processes, and then to adjust any procedures to acquire the necessary results. Students often do not write down steps taken to solve lab problems and do not practice lab procedures. Once they have completed the assigned lab, they do not research further other possibilities in solving said problem.

Information Technology students understand basic terminology exceptionally well. They can repeat terms and definitions, but they lack the ability to apply the lexicon within the communication process. This is often a result of poor comprehension of the material brought on by insufficient reading of the material. The IT students speed-read the material and most of the time they read the glossary or the bolded words for the definition. IT students also copy and paste definitions from the Internet or other sources to assignments because the course work are posted/graded on blackboard.

Action Plan: Provide Information Technology students the procedures, applications, and test/adjust analysis to examine their comprehension weaknesses and strengths so that they can better prepare themselves as effective network troubleshooters. Strengthen Terminology utilizing quizzes, readings, reports. Information Technology students possess a weakness in practicing troubleshooting processes. They have difficulty planning troubleshooting procedures and an inability to "talk the talk."

Program Outcome 2 - Plan, design, and develop a functional and secure network infrastructure.

Results: Information Technology students essentially grasp the basic security concepts. Above-satisfactory comprehension exists among these students due to the repetitive presentation, installation, and practice of security concepts, knowledge and application of permissions which stems from their comprehension of networking concepts, and the exposure to media/news concerning network security.

An area of apprehension is the ability to plan network security processes. Information Technology students exhibit a weakness in terms of identifying the processes needed to troubleshoot an existing problem they are unfamiliar with, applying Layer 2 and Layer 3 Technology concepts in solving network security problems, and the ability to apply performance and system monitoring standards when solving security problems.

Information Technology students also comprehend basic network security terminology. They can repeat terms and definitions, but they lack the ability to apply the terminology in their communication process. This is caused because 
of their struggle to read the material meticulously, the lack of exposure to real world network security issues, and to apply troubleshooting techniques at the network security level.

Action Plan: Information Technology students need to read materials carefully, more classroom discussion/labs need to be utilized to reinforce concepts, and possible study/lab groups to solve advanced network security issues. Students need to document network security procedures to reinforce best practices, per industry standards. Provide students with activities and labs that will provide students the environment to validate these practices. These action plans apply to ITS273 Information Security 1, ITA142 Network Operating Systems 1, and ITA195 Networking Operating Systems 2.

Program Outcome 3 - Implement support models based on best practices.

Results: Information Technology students demonstrate above-satisfactory levels of identifying the steps and procedures with Implement support models based on best practices. This is due to the due the repetitious best practices of information technology concepts in all three of their first quarters.

Areas in which Information Technology students fell below the satisfactory level including: applying best practices when dealing with questions that pertained to customer service, network Layer 2 and Layer 3 technology, and Network Operating Systems. Students were unable to apply their awareness base to situations due to a lack of exposure to customer service, the inability to apply previous learned routines from classes Networking 1 and 2 to labs and classes Network Operating Systems 1 and 2 that were unfamiliar, and to take OSI model rules and apply them in solving networking issues of Layer 2 and Layer 3 networking.

Information Technology students show the aptitude to apply prior understanding and previously learned practices to similar situations/problems. They can repeat terms and definitions, but they lack the ability to apply theses terminologies in their communication vernacular in advanced problem solving examples. This is caused by their struggle to read the material thoroughly and to research other possible solutions to the problem(s) at hand. IT students have the tendency to settle for what works versus what could work better.

Action Plan: Information Technology students need to read materials thoroughly, more classroom discussion/labs need to be utilized to strengthen customer service procedures and Network Layer 2 and Layer 3 technology. Another action plan is to inspire students to discover other best practices quite different than the one in the text book. IT students have beyond average understanding and practice of common network Layer 2 and Layer 3 concepts. Students can execute standard Layer 2 and Layer 3 instructions very well. IT students demonstrate trouble when hands/on more in-depth, when they are implementing advanced IP addressing concepts.

Deliver IT students' project-based networking labs that challenge them to apply former taught information and to apply best practices. This action plan applies to ITA126 Networking 1, ITA136 Networking 2, ITA142 Network Operating Systems 1, and ITA195 Networking Operating Systems 2.

Program Outcome 4 - Exhibit professional growth and meet the industry expectations of Information Technology Network Administration students.

Results: Very few Information Technology students showed above-satisfactory levels when exhibiting professional growth and meeting the industry expectations of Information Technology. None of the IT students performed at the exceptional level.

Two-thirds of the IT students fell below the satisfactory level when applying best practices dealing with questions related to course material covered in the first three quarters. IT student's development level to manage their expected learning processes is simply developing to the accepted level of a functional IT worker. IT students lack the ability to validate their reasoning levels through soft skills: written, verbal, problem solving, troubleshooting, and vocabulary.

Information Technology students show the ability to apply prior information and previously learned practices to similar situations/problems. They can repeat terms and definitions, but they lack the ability to apply the terminology in their communication process in advanced problem sets. This is likely the aftermath of students because of their 
resistance to read the material thoroughly and to research other possible solutions to the problem(s) at hand. Most students have the tendency to settle for what works versus what could work better.

Action plan: Information Technology students need to read materials thoroughly, more classroom discussion/labs need to be utilized to reinforce procedures and technologies introduced in the first three quarters. The action plan is to inspire students to discover other best practices besides the examples in the text books. IT students again need to read materials thoroughly and in detail. Additional lab work to introduce previous concepts. IT students need to communicate technology as a second language. Require students to utilize other resources like current events to aid them in problem solving labs. The Discussion Boards within the online learning component needs to be utilized to increase their soft skills in communicating and writing their knowledge of technology. This action will be applied to ITA124 Hardware Technology 1, ITA112 Desktop Operating Systems, ITA126 Networking 1, ITA136 Networking 2, ITA142 Network Operating Systems 1, ITA195 Networking Operating Systems 2, and ITS273 Information Security 1.

Table 2. Information Technology Average Score Breakdown

\begin{tabular}{|l|c|}
\hline \multicolumn{1}{|c|}{ Program Outcome for Information Technology } & Average Score \\
\hline $\begin{array}{l}\text { P1 - Configure, troubleshoot, and administer client or network } \\
\text { operating systems. }\end{array}$ & $71.30 \%$ \\
\hline $\begin{array}{l}\text { P2 - Plan, design, and develop a functional and secure network } \\
\text { infrastructure. }\end{array}$ & $78.40 \%$ \\
\hline P3 - Implement support models based on best practices. & $73.70 \%$ \\
\hline $\begin{array}{l}\text { P4 - Exhibit professional growth and meet the industry expectations } \\
\text { of Information Technology Network Administration students. }\end{array}$ & $58.70 \%$ \\
\hline
\end{tabular}

\section{CONCLUSIONS}

The biggest improvement growth documented is within Program Outcome \#4 for Information Technology is where students displayed professional growth and met the industry expectations for Information Technology. As Table 2 above describes, Information Technology students achieved 58.70\% average score in this area "Exhibit professional growth and meet the industry expectations of Information Technology Network Administration students." Nonetheless, the Computer Programming students achieved. 90\%. This then describes that within the next full year for the students one of the School of Information Technology departmental academic goals' is to ensure this student's strength before he/she graduates. Communication is one of the baggiest needs our IT Advisory Board requests from our students second to Technical skills. This transition will be a requirement for our School of Information Technology to modify.

Outside of Program Outcome 4 each of the students for Computer Programming and Information Technology has consistent results. Either in the 90\%'s for Computer Programming or 70\%'s for Information Technology. This then indicates that consistency and repetition does occur within the students learning. Nevertheless, having $90 \%$ as an average for all students program outcomes in Computer Programming had us change the assessment from only 10 multiple choice, 4 Short Question Responses and a programming lab to 25 multiple choice questions and a lab. We wanted to find more quantitative changes within the test questions as having $90 \%$ constant as an average indicates inconsistencies and a potential inaccurate assessment.

In a journal publication titled 'Learning in DEPTH: developing a graphical tool for professional thinking for technology teachers' by Frank Banks, he discusses how knowledge is created within schools: he specifies for a 'knowledge creating school' and suggests that such an organization will: 1) investigate the state of its intellectual capital, 2) manage the process of creating new professional knowledge, 3) validate the professional knowledge created, and 4) disseminate the created professional knowledge; thereby enabling technology teachers to develop their own 
curricula can be viewed as an important part of this knowledge creation and their ability to do this will depend on their personal subject construct. (2008).

These processes from Banks is ultimately the processes that a good academic team must ensure to provide the right amount of current knowledge for students to achieve. In the technology world, changes and updates are occurring every day. Innovation, creativity and having a sense of modernization within curriculum is a must to ensure the students technical comprehension.

We can see from the outcomes assessment data that not only have the students gained knowledge in each technical function but so did the academic team: within the maturity of how the academic process works. It's a win - win. This assessment was the School of Information Technology's first mid-assessment. The continued assessments for these students will also contain an end-assessment evaluation. However, through this process the team is ensuring the right amount of academic achievement outcomes, goals and strategies for the courses and the students. In a Technical College ensuring that assessments are up to date and active, it is key to ensure the right amount of technical interactions in the classes. Without this process, faculty will simply individually lead the course structures while this needs to be a departmental planned achievement, experience and goals. We are happy to see that our work, and planning of our assessments are being a positive impact to the students, department and institution.

The authors of this study are planning to conduct two additional studies in the future about how the end-point assessment impacts both Computer Programming and Information Technology students. Then, a follow-up will compare both mid-point and end-point assessments and examine the impact on students' education and curriculum. Pittsburgh Technical College's School of Information Technology is growing, and a full Bachelor's of Science degree in Information Systems and Technology will commence for the first time in July 2017. Additional studies will be developed, especially with this new degree program, as this is the first of two bachelor's degrees ever implemented (other being B.S.B.A.) at the College.

\section{REFERENCES}

Banks, F. (2008). Learning in DEPTH: Developing a Graphical Tool for Professional Thinking for Technology Teachers. International Journal of Technology and Design Education, 18(1), 221-229.

Casey, C. (2013). Building a Student-Centered Learning Framework using Social Software in the Middle Years Classroom: An Action Research Study. Journal of Information Technology Education: Research, 12(1), 159-189.

Community College Weekly, Top 50 Associate Degrees: Computer and Information Sciences \& Support Services and Top 50 Associate Degrees: Engineering Technologies and Engineering-Related Fields [http://ccweek.com/articles.sec-17-1-top-100-charts.html]. (2016). Retrieved February, 32017.

Farooq, M., Chaudhry, A., Shafiq, M., \& Berhanu, G. (2011). Factors Affecting Student's Quality of Academic Performance: A Case of Secondary School Level. Journal of Quality and Technology Management, 7(2), 114.

Gillard, S., Bailey, D., \& Nolan, E. (2008). Ten Reasons for IT Educators to be Early Adopters of IT Innovations. Journal of Information Technology Education, 7(1), 21-33.

Henson, K., \& Kamal, M. (2010). Closing The Gap - Information Systems Curriculum And Changing Global Market. American Journal of Business Education, 3(5), 17-20.

Koohang, A., Riley, L., Smith, T., \& Floyd, K. (2010). Design of an Information Technology Undergraduate Program to Produce IT Versatilists. Journal of Information Technology Education, 9(1), 99-113. 
Lightfoot, J. (1999). Fads Verses Fundamentals: The Dilemma for Information Systems Curriculum Design. Journal of Education for Business, 75(1), 43-50.

Poindexter, S. (2003). Assessing Active Alternatives for Teaching Programming. Journal of Information Technology Education, 2, 257-265.

Reichgelt, H., Lunt, B., Ashford, T., Phelps, A., Slazinski, E., \& Willis, C. (2004). A Comparison of Baccalaureate Programs in Information Technology with Baccalaureate Programs in Computer Science and Information Systems. Journal of Information Technology Education, 3(1), 19-34.

Valenti, S. (2003). Information Technology for Assessing Student Learning. Journal of Information Technology Education, 2(1), 181-184.

Vars, G. (2000). Common Learnings: A 50-Year Quest. Journal of Curriculum and Supervision, 16(1), 70-89.

Zhang, A., Aasheim C. (2011). Academic Success Factors: An IT Student Perspective. Journal of Information Technology Education, 10(1), 309-331. 